\title{
Cognitive Impairment Prevalence and Impact on Quality of Life for Patients after Cardiac Surgery
}

\author{
Ruta Bendikaite, MSc, Renata Vimantaite, MD \\ Lithuanian University of Health Sciences Medical Academy Faculty of Nursing, Kaunas, Lithuania
}

\section{ABSTRACT}

Cognitive impairment is a common complication after cardiac surgery. It complicates not only the patient's recovery and return to normal life, but also has a negative impact on quality of life.

Objective: The aim of this study was to investigate the prevalence of cognitive impairment and its impact of quality of life for patients after cardiac surgery.

Results: Before cardiac surgery, mild cognitive impairment was determined to be 20.8 percent and moderate cognitive impairment was 3.3 percent. After surgery, mild cognitive impairment almost doubled to 46.1 percent and moderate cognitive impairment increased to 4.9 percent. Older age, lower education, smoking, and prolonged hospitalization before surgery impacts cognitive impairment. Postoperative cognitive impairment is influenced by older age, prolonged hospitalization before surgery, prolonged operation, mechanical ventilation, and duration of cardiopulmonary bypass. For patients without cognitive impairment before cardiac surgery, general health assessment improved the most without reduced vitality/viability. For patients whose cognitive impairment significantly improved physical activity, pain sensation, and general health assessment improved slightly.

Conclusions: Preoperative cognitive impairment was determined in 1/4 of our patients. Mild cognitive impairment after surgery was slightly increased. Older age, lower education, and prolonged hospitalization before surgery have an impact on cognitive impairment before and after surgery.

\section{INTRODUCTION}

In 1948, World Health Organization (WHO) issued a definition of patients related to quality of life: Quality of life is an individual assessment of their purpose in life culture and value systems in which the individual lives, in terms related to his purposes, hopes, interests and standards. This is a rather broad concept, which is a complex influence of a person's physical health, psychological state, social relations,

Received December 2, 2019; accepted fune 16, 2020.

Correspondence: Ruta Bendikaite, MSc, Lithuanian University of Health Sciences Medical Academy Faculty of Nursing, Kaunas, Lithuania, Lithuanian University of Health Sciences Kaunas Clinics Department of Cardiology (e-mail:Ruta.Bendikaite@kaunoklinikos.lt). and communication with a person's surrounding environment [Kazlauskaitė 2005; Staškutė 2014; Faeyrs 2013]. Quality of life is determined by many factors and circumstances: housing, employment, income, family life, social support, stress, health, health care access, working conditions, nutrition, education, and other opportunities. Scientific data show that only a healthy person can be physically, mentally, and socially capable of acting and feeling of a positive emotional state: satisfaction and happiness, and all these things the most important components of quality of life [Krančiukaitė 2007]. Improving a patient's quality of life is one of the most important goals in cardiac surgery. It is related to the disease, symptoms and side effects caused by the treatment and surgery; quality of life can be based on how patients perceive and experience these events in their daily activities [Noyez 2011]. Despite the improvement of surgical techniques and effective neuroprotective measures, brain injury after cardiac surgery remains relatively constant over the years because patients are older and have more illnesses [Bruggemans 2013]. A variety of authors found cognitive impairment can be determined in up to 53 percent of patients in the early postoperative period and, after a few years, it may persist in about 20 percent of treated patients [Norkienè 2008]. Cognitive impairment after cardiac surgery has a direct impact on the patient's quality of life [Rudolph 2010]. Cognitive impairment can be described by reduced memory, concentration, language, and social integration, which frequently occurs after surgical procedures and can last for the rest of the patient's life [Martin 2008].

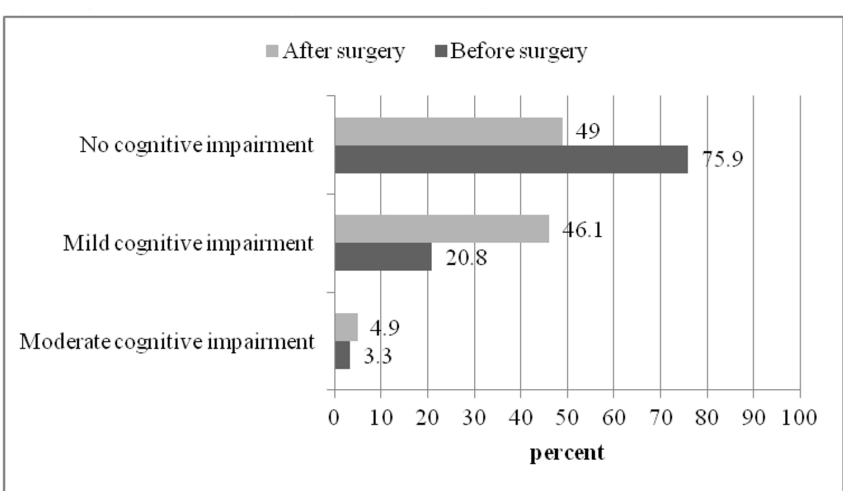

Figure 1. Cognitive impairment prevalence before and after cardiac surgery. *- $\chi^{2}$ test; $P<.05$ 


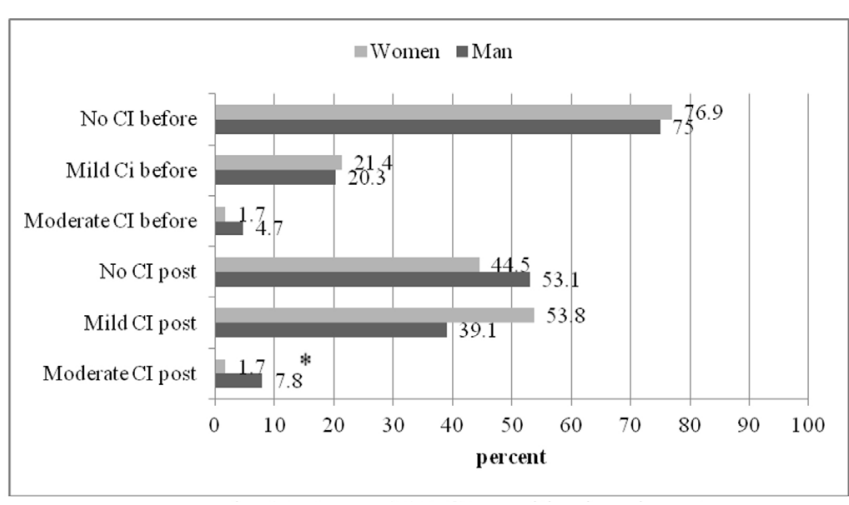

Figure 2. Cognitive impairment prevalence before and after cardiac surgery by sex. *- $\chi^{2}$ testas; $P<.05 ; \mathrm{Cl}$, cognitive impairment

\section{MATERIALS AND METHODS}

The study involved patients of the Hospital of Lithuanian University of Health Sciences Kaunas Clinics Department of Cardiac Surgery. These patients came for planned surgery (coronary artery bypass grafting, heart valve prothesis/plastic). The sample was based on the average of the last three years of surgery. To investigate the prevalence of cognitive impairment, the MMSE test was used as well as a patient assessment questionnaire by researchers to assess perioperative factors and quality of life. The study was performed with the permission of the Lithuanian University of Health Sciences Bioethics Center. The patient survey was conducted in three stages: 1) The day before surgery to assess quality of life and cognitive function; 2) Six days after surgery to assess cognitive function; and 3) One month after surgery to assess quality of life. Study inclusion criteria included patients going in for planned cardiac surgery, and patients who understood and were able to write in Lithuanian.

Statistical data analysis: The research data analysis was performed using SPSS 17.0 (Statistical Package for the Social Sciences) and Excel 2010. Serial distribution of the selected sample used to evaluate data descriptive statistics - absolute (n) and percentage rates (percent). Quantative data were presented as arithmetic averages (m) with standard deviation (SD). Tables were created to assess attributes; characteristics to determine dependence were calculated with chi-squared $\left(\chi^{2}\right)$ criterion. Quantative data distribution normality was assessed with Kolmogorov-Smirnov test. Two dependent samplings of quantative variables whose distribution was not statistically significant to normal and average values were compared using Student's $t$ test. Two independent samples of quantative variables with a distribution significantly different to the normal and average values were compared using the Mann-Whitney $U$ test. Binary variable dependence on independent variables were used to assess binary logistic regression, the relationship between the dependent variable, and several independent variables to determine linear multiple regression. Regression model was used to determine the suitability of Negelkerke calculated determination coefficient $\left(\mathrm{R}^{2}\right)$ and corrected determination coefficient. When $\mathrm{R}^{2}>0.2$,

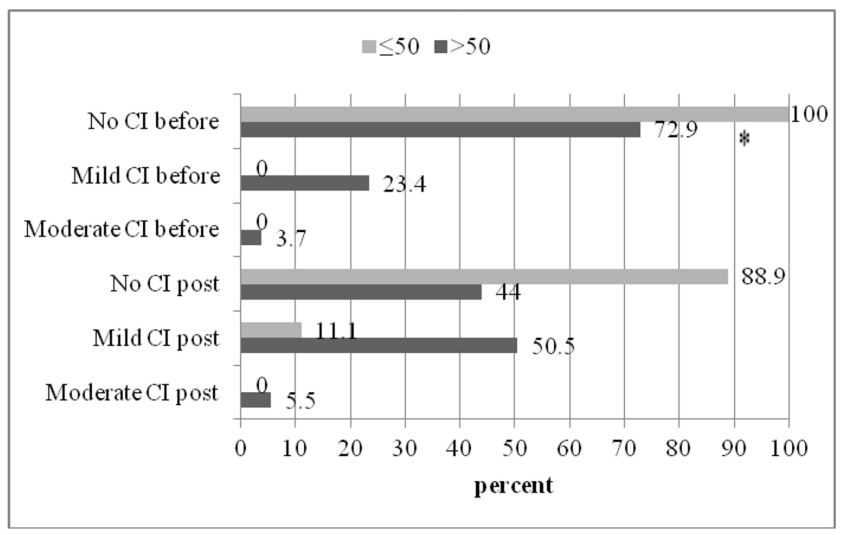

Figure 3. Cognitive impairment prevalence before and after cardiac surgery by education. ${ }^{*}-\chi^{2}$ testas; $P<.05 ; \mathrm{Cl}$, cognitive impairment

the model was considered appropriate. A level of $P \leq .05$ was considered to be statistically significant.

\section{RESULTS}

The prevalence of cognitive impairment: The study confirmed that cognitive impairment is a fairly common complication after cardiac surgery. With regard to the assessment of cognitive functions of patients and their prevalence of damage before cardiac surgery, the study showed that about one in four patients (20.8 percent) had mild preoperative cognitive impairment, which almost doubled after surgery to 46.1 percent. The average cognitive impairment was only 3.3 percent, which increased slightly after surgery to 4.9 percent (Figure 1).

The research sample of women without cognitive impairment was significantly higher (76.9 percent) than men (75.0 percent). Mild cognitive impairment before surgery was nearly the same: 21.4 percent in women and 20.3 percent in men. Average cognitive impairment had only a small percentage of patients (1.7 percent in women and 4.7 percent in men). After cardiac surgery, cognitive impairment ratio by gender significantly changed with damage more common in men than in women $(\mathrm{P}<.05)$. It was found that mild postoperative cognitive impairment was more common in women (53.8 percent) than in men (39.1 percent). This is more than double, from 21.4 percent to 53.8 percent. Moderate cognitive impairment cases often were more in men (7.8 percent) than in women (1.7 percent); for women this figure is unchanged (Figure 2).

To assess cognitive impairment in connection with its formation, it was found that mild cognitive impairment prior to and after surgery was more common among patients with secondary (20.0 percent) and baseline (47.4 percent) education. After cardiac surgery, this damage frequency almost doubled to 51.7 percent with secondary education and 71.1 percent with primary education $(\mathrm{P}<.05)$. Therefore, it can be assumed that age influences cognitive impairment (Figure 3).

The study found that patients with cognitive impairment were older; the average age was 66.9 years compared with those without cognitive impairment (average age 57.6) $(P<.05)$. According 
Perioperative factors against cognitive function after cardiac surgery $(\mathrm{N}=245)$

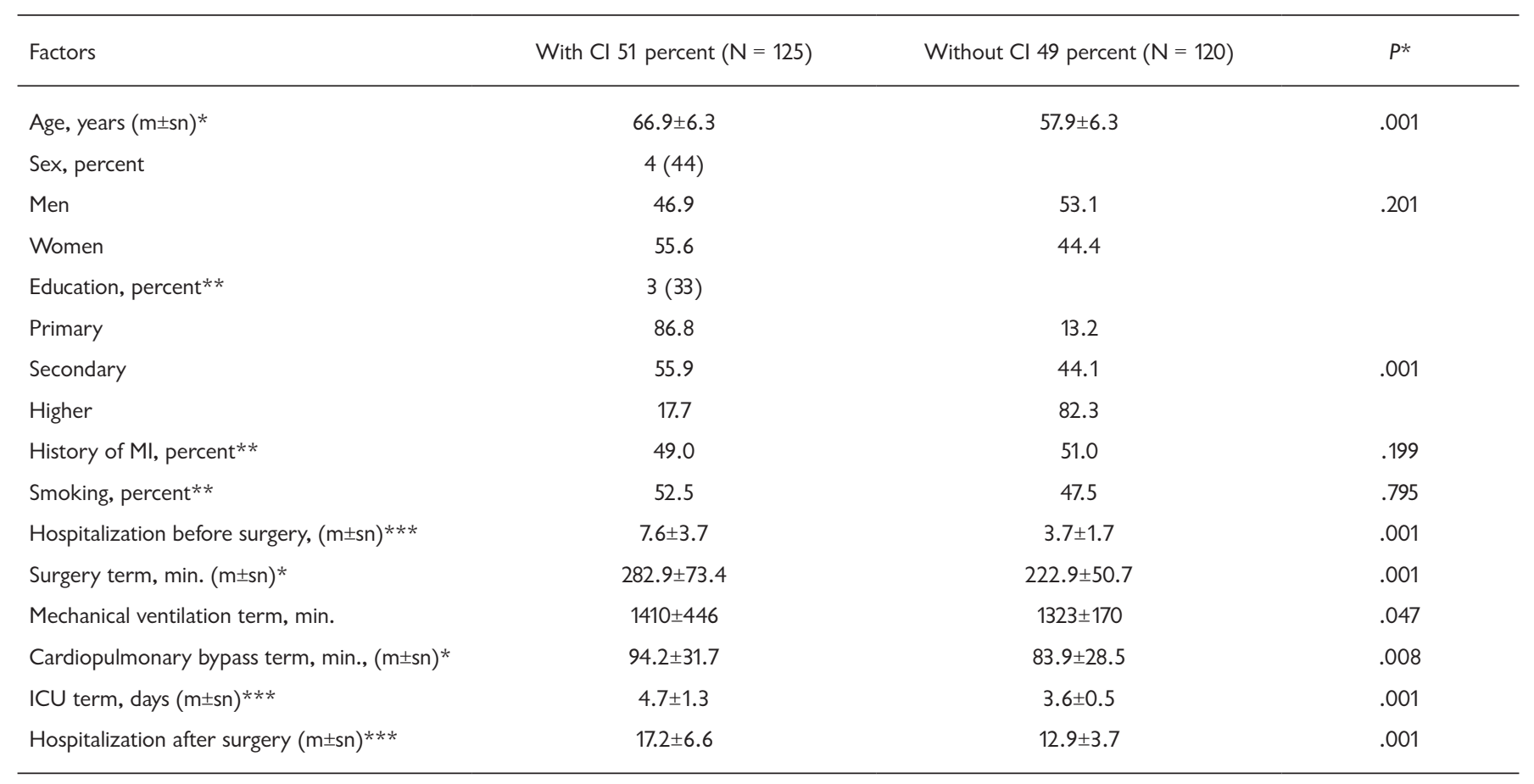

*Student t-test; **- $\chi^{2}$ test; ***Mann-Whitney $U$ test; MI, myocardial infarction; ICU, intensive care unit; $\mathrm{Cl}$, cognitive impairment

to gender, the comparison indicates this is not related to cognitive impairment $(P>.05)$. Also, cognitive impairment was not related to smoking habits or history of $\mathrm{MI}(P>.05)$.

Patients with cognitive impairment spent more days in the hospital before surgery (average 7.6 days) than those without this damage (average of 3.7 days) $(P<.05)$. Patients with postoperative cognitive impairment had prolonged surgery (mean 282.9 minutes), longer artificial lung ventilation (approximately 1410 minutes), and artificial blood circulation time (average 94.2 minutes) $(P<.05)$. Also, they spent more time in the intensive care unit (average 4.7 days) and more days in the hospital after surgery (average 17.2) $(P<.05)$ (Table).

Changes to quality of life before and after cardiac surgery: The results showed that patients without cognitive impairment prior to cardiac surgery had the most improved general health assessment (GHA) (11.48 points), but also the most deteriorated energy/vitality (EV) (-17.14 points). They also had a nearly unchanged emotional state (ES) at 0.36 points (Figure 4).

Results of the assessment of patients with cognitive impairment showed that the highest positive change in activity appeared limited, due to emotional problems (AE) (35.02 points), as well as the restriction of activities, due to physical problems (PA) (22.20 points). The biggest negative change appeared in energy/vitality assessment (EV) (-14.58 points) (Figure 5).

As with any health-related intervention when patients experience physical and emotional difficulties, heart surgery certainly changes one's quality of life. In this study, patient quality of life was assessed the day before surgery and four weeks after surgery. Depending on the patient's cognitive impairment prior to surgery, post-heart surgery changed some aspects of their quality of life. Patients with prior heart surgery showed cognitive impairment significantly improved the overall state of health (GHA - 11.48). Before cardiac surgery, patients who had cognitive impairment reported significantly less restriction to activities both physical (AP - 22.20) and emotional (AE - 35.02); they also suffered less pain $(P-$ 17.41) $(P<.05)$. However, both groups reported significantly deteriorated exuberance/vitality $(P<.05)$ (Figure 6$)$.

\section{DIscussion}

Coronary artery bypass grafting surgery is one of the most frequently performed operations worldwide. It often is accompanied by postoperative impairment of cognitive complications [Farhoudi 2010; Sun 2012]. The surgery always is performed with the same purpose - to improve the patient's health. However, many factors can have a negative impact on the objectives of the surgery, so it is important to identify and control them [Scott 2014].

Postoperative cognitive impairment is a well-recognized complication after cardiac surgery. Older age, lower education, history of stroke [Diederik 2007], cerebral embolization, systemic inflammatory response and cerebral hypoperfusion generally are associated with the short-term cognitive impairment after surgery [Djaiani 2012]. It is a more fully described complication that can occur. Robinson et al. studied older patients, whose average age was 73 years. The study looked at a total of 186 patients, of whom 82 patients ( 44 percent) had preoperative cognitive impairment. Robinson found more 


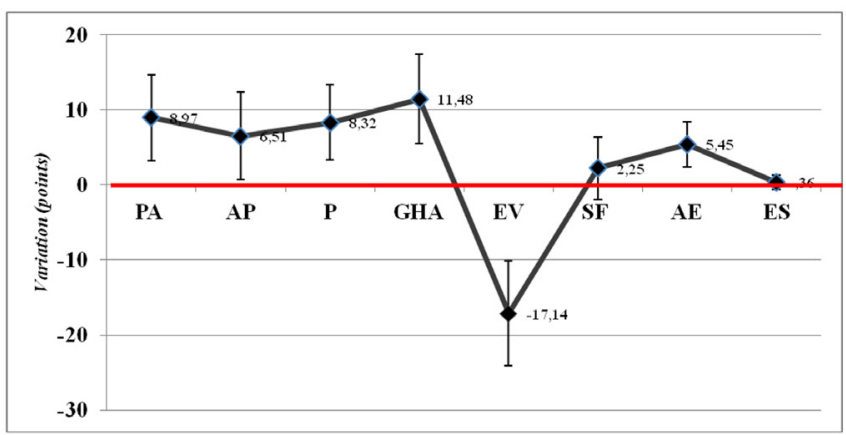

Figure 4. Patients before cardiac surgery who had no cognitive impairment, quality of life subscales assessment change after surgery. PA, physical activity; AP, activity limitations due to physical problems; $P$, pain; GHA, general health assessment; EV, energy/vitality; SF, social function; $\mathrm{AE}$, activity limitations due to emotional problems; ES, emotional state

than one complication after surgery $(P=.011)$, longer time spent in the hospital $(P=.001)$, higher mortality within six months $(P=.04)$, and a higher incidence of reciprocity to the hospital after 30 days $(P=.033)$. Cognitive impairment of the number of cases by age was 60 years (17 percent) $(11 / 63), 70$ m. (52 percent) (47/90), $80 \mathrm{~m}$. (63 percent) (19/30), and $90 \mathrm{~m}$. (100 percent) (3/3) [Robinson 2012].

The study found that preoperative cognitive impairment is influenced by older age, lower education, smoking, and longer time spent in the hospital before the surgery. In addition to older age and longer time spent in the ICU, postoperative cognitive impairment was affected by prolonged mechanical ventilation and cardiopulmonary bypass duration. Norkienè et al indicates that cognitive impairment is associated with postoperative factors, such as increased bleeding, hemodynamic instability, delirium, or arrhythmias. Older age, carotid artery stenosis, prolonged surgery, and artificial lung ventilation increased the possible development of cognitive impairment [Norkiené 2010]. Kozora et al also distinguish between an older age, lower education, and impaired cognitive function before surgery as risk factors of postoperative cognitive

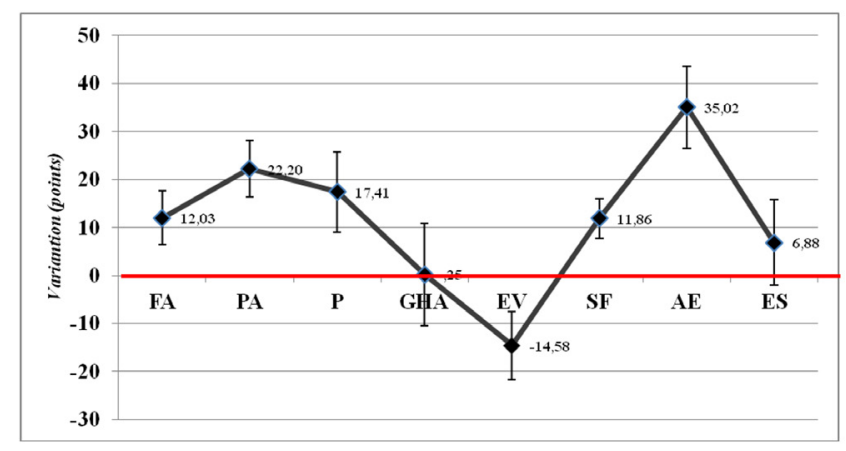

Figure 5. Assessment of quality of life on patients with cognitive impairment before cardiac surgery. PA, physival activity; AP, activity limitations due to physical problems; P, pain; GHA, general health assessment; EV, energy/vitality; SF, social function; AE, activity limitations due to emotional problems; ES, emotional state

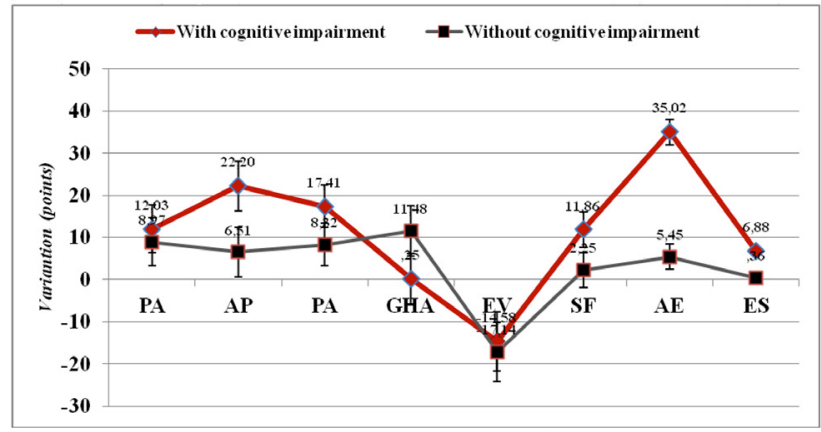

Figure 6. Changes of quality of life scales after cardiac surgery and depends on the cognitive impairment. PA, physical activity; AP, activity limitations due to physical problems; P, pain; GHA, general health assessment; EV, energy/vitality; SF, social function; AE, activity limitations due to emotional problems; ES, emotional state

impairment [Kozora 2010].

Based on the results of this study and that of previous studies, it can be assumed that older age, lower education, impaired cognitive function before surgery, longer term of the surgery, prolonged time spent in the intensive care unit, and prolonged length of hospital stay influence cognitive impairment after surgery.

A patient with cognitive impairment prior to surgery may experience quality of life after surgery. However, if focusing only on an individual's quality of life, not all will significantly improve and even some may significantly decline. Patients with and without cognitive impairment do experience significantly deteriorated energy/vitality.

\section{CONCLUSIONS}

Mild preoperative cognitive impairment occurs in every fourth patient. After cardiac surgery, mild cognitive impairment almost doubled, while the average cognitive impairment slightly increased. Surgery-related factors, such as prolonged surgery and cardiopulmonary bypass duration, have a significant impact on the cause of cognitive impairment decline. Patients who did not have cognitive impairment after surgery significantly improved in general health and deterioration in energy/vitality assessments and suffered less pain. After cardiac surgery, patients without cognitive impairment had improved quality of life after surgery. Patients with cognitive impairment experienced significant improvements in performance limitations due to physical problems, physical activity and pain sensation, and energy/ vitality significantly deteriorated. After cardiac surgery, patients with cognitive impairment reported improved quality of life after surgery.

\section{ACKNOWLEDGEMENTS}

The authors gratefully acknowledge the patients who agreed to participate in this respective study. Also, the authors thank The Hospital of Lithuanian University of Health 
Sciences Department of Cardiac, Thoracic and Vascular Surgery for the permission to perform the investigation.

\section{REFERENCES}

Bruggemans EF. 2013. Cognitive dysfunction after cardiac surgery: pathophysiological mechanisms and preventive strategies. Neth Heart J 21:70-73.

Diederik van D, Spoor M, Hijman R, et al. 2007. cognitive and Cardiac Outcomes 5 Years After Off-Pump vs On-Pump Coronary Artery Bypass Graft Surgery. JAMA 7(297):701-708.

Djaiani G, Katznelson R, Fedorko L, et al. 2012. early benefit of preserved cognitive function is not sustained at one-year after cardiac sugery: a longitudinal follow-up of the randomized controlled trial. Canadian Anesthesiologists Journal 59:449-455.

Faeyrs P, Machin D. 2013. Quality of Life: The Assessement, Analysis and Interpretation of Patient Reporeted Outcomes. Second Edition. 20-23.

Farhoudi M, Mehrvar K, Afrasiabi A, et al. 2010. Neurocognitive impairment after off-pump and on-pump coronary artery bypass graft surgery an Iranian experience. Neuropsychiatric Disease and Treatment 6:775-778.

Kazlauskaitè M, Rèklaitienè R. 2005. Vidutinio amžiaus Kauno gyventojų gyvenimo kokybè. Medicina 41(2):155-161.

Kozora E, Kongs S, Collins FJ, et al. 2010. Cognitive Outcomes After On - Versus Off-Pump Coronary Artery Bypass Surgery. The Annals of Thoracic Surgery 90:1134-1141.

Krančiukaitė D, Rastenytė D, Jurẻnienė K. 2007. Kauno populiacijos gyvenimo kokybès vertinimas naudojant SF-12 klausimyną. Medicina 43(6):501-507.

Martin JFV, Melo RO, Sousa LP. 2008. Postoperative cognitive dysfunction after cardiac surgery. Rev Bras Cir Cardiovasc 23(2): 245-255.

Norkienė I, Budrys V, Kaubrys G, ir kt. 2010. Ankstyvas kognityviniu funkcijų pakenkimas po vainikinių arterijų apeinamųjų jungčių suformavimo operacijų, rizikos veiksniai ir asimptominès miego arterijos stenozės itaka. Neurologijos seminarai 14(43):35-39.

Norkienė I, Ivaškevičius J. 2008. Pažintinių funkcijų sutrikimai po kardiochirurginių operacijų: intraoperacinių veiksnių įtaka. Lietuvos chirurgija 6(2):134-140.

Noyez L, Jager MJ, Maroku ALP. 2011. Quality of life after cardiac surgery: underresearched research. Interactive CardioVascular and Thoracic Surgery 13:511-515.

Robinson NTh, Wu SD, Pointer FL, et al. 2012. Preoperative Cognitive Dysfunction Is Related to Adverse Postoperative Outcomes in the Elderly. J Am Coll Surg. 215(1):12-17.

Rudolph JL, Schreiber KA, Culley DJ, et al. 2010. Measurement of postoperative cognitive dysfunction after cardiac surgery: a systematic review. Acta Anaesthesiol Scand 54(6):663-677.

Scott AD, Evered AL, Silbert SB. 2014. Cardiac Surgery, the Brain, and Inflammation. The Journal of ExtraCorporeal Technology 46:15-22.

Staškutė I. 2014. Su sveikata susisjusios gyvenimo kokybès samprata, stebėsenos ir vertinimo metodai bei reikšmè sveikatos politikoje. Sveikatos politika ir valdymas $1(6): 7-19$.

Sun X, Lindsay J, Monsein H.L, et al. 2012. Silent Brain Injury After Cardiac Surgery: A Review. Journal of the American College of Cardiology. 9(60): 791-797. 